clearly low and their serum ApoB concentrations about half that of normal subjects. The patient's daughter also had an undetectable serum $\mathrm{Lp}(\mathrm{a})$ lipoprotein concentration. $\mathrm{Lp}(\mathrm{a})$ lipoprotein has been shown to be a cardiovascular risk factor. ${ }^{2-4}$ The observation of undetectable serum $\mathrm{Lp}$ (a) lipoprotein concentrations in heterozygotes for hypobetalipoproteinaemia merits further study as to the underlying biochemical mechanisms for its in vivo control. It is suggested that ApoB is in some way involved in the production of the $\mathrm{Lp}$ (a) particle.

It has been reported that subjects with this condition have a lower incidence of coronary artery disease than would be expected for the general population. ${ }^{7}$ This could in part be due to their low LDL cholesterol, as well as to a low serum $\mathrm{Lp}$ (a) lipoprotein concentration.

Herbert et $a l^{7}$ noted that HDL cholesterol concentrations in hypobetalipoproteinaemia are variable, with some subjects having low HDL cholesterol concentrations and others normal levels. In our family the index patient had a low HDL cholesterol concentration, whereas her son and father had normal levels. It is also of note that the triglyceride content of the HDL particles of the affected family members was low.

We are grateful to Dr S Amiel for kind permission to report this patient and to Dr M Mattock and the Metabolic Medicine Department for their help with this study.

1 Collins DR, Knott TJ, Pease RJ, Powell LM, Wallis SC Robertson S, et al. Truncated variants of apolipoprotein $B$ causes hypobetalipoproteinaemia. Nucleic Acid Res 1988; 16:8361-75.

2 Scanu AM. $\mathrm{Lp}(\mathrm{a})$ as a marker of coronary artery disease. Clin Cardiol 1991;14:35-9.

3 Utermann G. Lipoprotein (a): a risk factor for premature coronary artery disease. Curr Opin Lipidol 1990;1:404-10.

4 Dahlen GH. The pre-beta-1-lipoprotein phenomenon in relation to serum cholesterol and triglyceride levels, the Lp(a) lation to serum cholesterol and triglyceride levels, the Lp(a)
lipoprotein and coronary heart disease. Acta Med Scand lipoprotein and

5 Havel RJ, Eden HA, Bragdon JH. The distribution and chemical composition of ultracentrifugally separated lipoproteins in human serum. $\mathcal{F}$ Clin Invest 1955;34:1345-53.

6 Farese RV, Linton MF, Young SG. Apolipoprotein B gene mutations affecting cholesterol levels. $\mathcal{F}$ Intern Med 1992; 231:643-52.

7 Herbert PN, Assman G, Gotto AM, Frederickson DS. Familial lipoprotein deficiency. In: Stanbury JB, Wyngaarden JB, Frederickson DS, Goldstein IL Brown MS, eds. Metabolic basis of inherited disease, 6th ed New York. MetaHill, 1989:589-621.

\title{
Gastric polyposis caused by multiple carcinoids and early carcinoma
}

\author{
S Bhatnagar, A Borg-Grech
}

Blackburn Royal Infirmary, Blackburn $S$ Bhatnagar A Borg-Grech

Correspondence to: Dr S Bhatnagar, 10 Burnham Close Cheadle Hulme, Cheshire SK8 6DN.

Accepted for publication 13 October 1994

\begin{abstract}
A case of gastric polyposis caused by multiple carcinoids with concurrent gastric carcinoma is reported in a 70 year old woman with severe atrophic gastritis and intestinal metaplasia. On microscopic examination, the carcinoids and gastric carcinoma arose separately thus representing "double primaries". Long-standing hypergastrinaemia probably plays a causative role in the development of carcinoma and carcinoids. Carcinoid tumours, although of low malignant potential, may be important as indicators of other unrelated high risk malignancies. Patients with carcinoids should be followed closely, especially as the incidence of these tumours seems to be on the increase.

(f Clin Pathol 1995;48:589-591)
\end{abstract}

Keywords: Stomach, carcinoid, adenocarcinoma.

The stomach is an uncommon site for carcinoids and multiplicity of carcinoid tumours is even rarer. Coexistence of adenocarcinoma with these multiple carcinoids is very rare indeed and very few such cases have been reported in the literature. ${ }^{1-3}$

\section{Case report}

A 70 year old Polish woman was admitted with a history of weight loss of over two stones over two years and occasional chest pains. There was a family history of malignancy. Her brother and father had both died of gastric carcinoma, a sister had died of hepatic carcinoma, and a daughter had carcinoma of the uterus. A barium enema was negative but barium meal examination revealed multiple gastric polyps. Intestinal polyposis was not present.

\section{Methods}

Endoscopic biopsy specimens ranging in size from 0.3 to $0.5 \mathrm{~cm}$ were obtained from three polyps. A larger polyp measuring $2.3 \times 1.6 \times$ $1 \cdot 2 \mathrm{~cm}$ was also removed for histological assessment. 


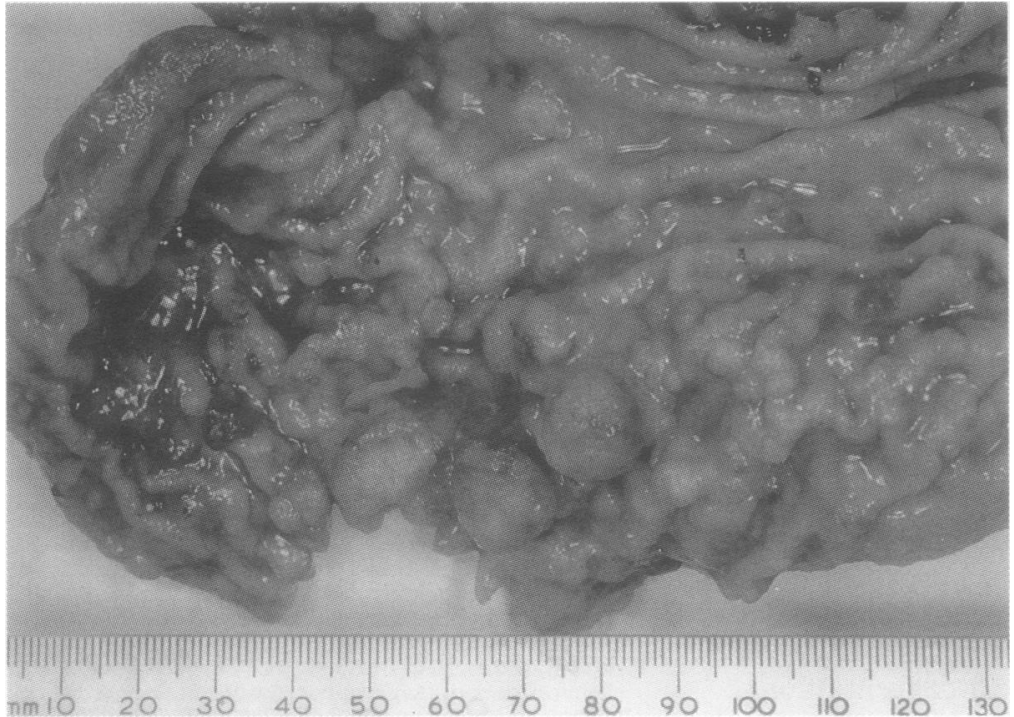

Figure 1 Gastrectomy specimen with multiple mucosal polyps.

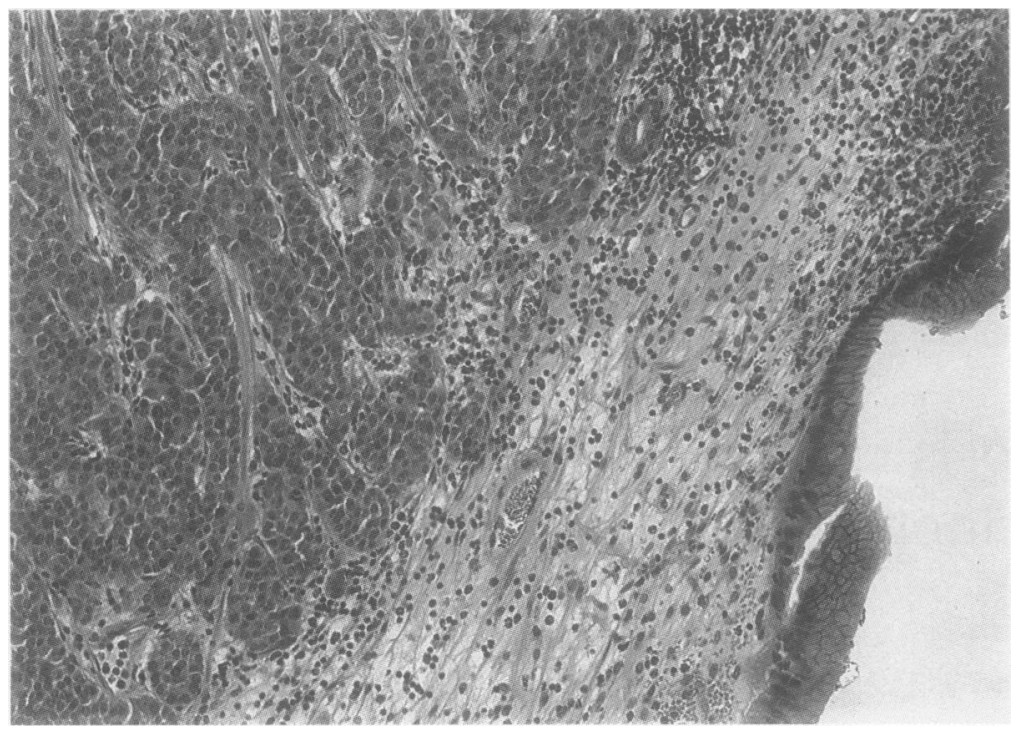

Figure 2 Flattened mucosa overlying a carcinoid nodule with the characteristic insular pattern. nodes were also sampled. The tissue was fixed in buffered formalin and stained using haematoxylin and eosin. Selected blocks were stained with diazo, grimelius, chromogranin (Lipshaw), epithelial membrane antigen (EMA) (Dako), Cam 5.2 (Becton Dickinson), $\alpha$ human chorionic gonadotropin (HCG) (Dako), and polyclonal gastrin (Lipshaw). Immunoperoxidase staining was performed at room temperature with the labelled Streptavidin-biotin complex technique. The primary antibody for EMA was diluted 1 in 75 and for $\alpha$-HCG 1 in 100; the other antibodies were bought prediluted. Appropriate positive and negative controls were included.

Electron microscopy was performed on selected areas of the formalin fixed specimen.

\section{LIGHT MICROSCOPIC EXAMINATION}

Pre-gastrectomy biopsy specimens included a hyperplastic polyp, two submucosal carcinoids and a "possible adenocarcinoma with neuroendocrine features".

In the gastrectomy specimen most of the polyps were composed of proliferating groups of uniform cells in the lamina propria with round nuclei and granular cytoplasm. These cells were arranged in characteristic solid nests, trabeculae and ribbon-like patterns. The covering epithelium was flattened and focally ulcerated (fig 2). A few of these carcinoids showed mild atypical features of nuclear enlargement, pleomorphism and multinucleation; however, increased mitotic activity was not a feature.

A single polyp showed features of tubulovillous adenoma with a well differentiated adenocarcinoma (intestinal-type by Lauren's classification) confined to the submucosa.

The intervening mucosa contained a patchy chronic inflammatory cell infiltrate and showed hyperplasia of similar carcinoid-like cells forming micronests. Extensive intestinal metaplasia of the epithelium and complete loss of parietal cells were also apparent. Helicobacter-like organisms were not seen. One of the perigastric lymph nodes contained metastatic carcinoid but there was no evidence of metastatic adenocarcinoma. raised serum gastrin concentrations of $400 \mathrm{pg}$ $\mathrm{ml}$ (normal $<40 \mathrm{pg} / \mathrm{ml}$ ), a normal urinary 5hydroxyindoleacetic acid concentration, and a normal full blood count. Serum $B_{12}$ concentrations were not determined. A total gastrectomy was performed two months after initial presentation.

\section{MACROSCOPIC EXAMINATION}

The gastrectomy specimen measured $14 \mathrm{~cm}$ along the lesser curvature, $27 \mathrm{~cm}$ along the greater curvature and included $1 \mathrm{~cm}$ of the distal oesophagus. The stomach mucosa contained over 50 sessile and pedunculated polyps ranging in size from 0.3 to $2.0 \mathrm{~cm}$ (fig 1 ). The small amount of attached fibrofatty connective tissue contained several firm lymph nodes ranging in size from $0.4 \times 0.2$ to $1.2 \times 0.5 \mathrm{~cm}$.

Multiple blocks were taken from several polyps, the intervening mucosa and both resected margins. Enlarged perigastric lymph

\section{IMMUNOHISTOCHEMISTRY}

The "carcinoid" cells of the sampled gastric polyps and intervening mucosa were strongly argyrophilic, not argentaffinic and strongly positive for chromogranin. These cells were negative for gastrin and focal positivity for $\alpha-H C G$ was present. The antral mucosa contained large numbers of gastrin positive cells. Focal $\alpha-\mathrm{HCG}$ positivity was also present in the solitary metastatic carcinoid in the lymph node. The adenocarcinoma was negative for chromogranin, gastrin and $\alpha-\mathrm{HCG}$ but was positive for EMA and Cam 5.2.

\section{ELECTRON MICROSCOPY}

The "carcinoid" cells contained typical intracytoplasmic granules and abundant rough endoplasmic reticulum. Adenocarcinomatous 
areas were of characteristic appearance with microvilli, irregular nuclei with large nucleoli and intracytoplasmic lumina.

\section{Discussion}

It is difficult to determine the true incidence of gastric carcinoids. In the literature the cited incidence is of 3 to $4 \%$ of all gastrointestinal carcinoids and only $0.02 \%$ of all gastric tumours. ${ }^{45}$ However, more recent studies claim an incidence of around $30 \%$ of all gastrointestinal carcinoids. ${ }^{2}$ This increase appears to be a result of both an increased ability to recognise these tumours (secondary to the introduction of routine endoscopic gastroscopy) and iatrogenic hypergastrinaemia, induced by $\mathrm{H}_{2}$ receptor blockers and proton pump inhibitors.

Gastric carcinoids seldom present with the typical carcinoid syndrome. The usual presentation is with pain, bleeding or anaemia. Rarely, an atypical carcinoid syndrome characterised by a red flushing is seen. This is thought to be caused by 5-hydroxytryptamine or histamine release by these tumours. ${ }^{6}$

Two types of gastric carcinoids have been described: those composed of enterochromaffin-like (ECL) cells and rare gastrinomas composed of $\mathrm{G}$ cells. The ECL tumours are often polypoid, multiple, strongly argyrophilic, and gastrin negative. The antrum is usually not involved. By contrast, the gastrinomas are often solitary, involve the antrum and do not react with silver strains. ${ }^{7}$ We shall confine our discussion to the former.

Most of these ECL cell tumours arise in patients with atrophic gastritis and intestinal metaplasia with or without associated pernicious anaemia. In contrast to gastrinomas they are only occasionally present in association with Zollinger-Ellision syndrome or as part of the syndrome of multiple endocrine adenomatosis. The common factor in all these cases is hypergastrinaemia. Gastrin is trophic to ECL cells and these carcinoid tumours seem to follow the sequence of chronic hormonal stimulation leading to hyperplasia and eventual neoplasia. Hyperplastic/ECL cells often present in the adjacent mucosa are regarded as carcinoid precursors. ${ }^{25}$

Clinically, ECL carcinoids seem to have a low to moderate malignant potential and this is reflected in their histological appearance. The nuclei are usually regular and normochromatic, mitoses are scanty and necrosis is absent. Regional metastasis occurs in up to $28 \%$ of cases and in these cases, focal atypical features of cellular pleomorphism and increased mitotic activity are usually present. However, the histological and cytological appearances of endocrine tumours are not a reliable indication of malignancy, the only important diagnostic criteria being distant metastases, vascular space permeation and extensive invasion of adjacent tissue. ${ }^{6}$

A recent development in the study of carcinoids has been the identification of scattered $\alpha-H C G$ positive cells found in many carcinoids. A more functional indication of malignancy in carcinoid tumours based on the production of $\alpha-H C G$ has been proposed recently. Maximum expression of this hormone was observed in the intermediate stages of the "hyperplasiadysplasia-neoplasia sequence" of development of ECL carcinoids in one series. ${ }^{2}$

Gastric carcinomas in association with gastric carcinoids present either in a composite form with an intimate admixture of the two components or as two separate components representing "double primaries". The case presented here belongs to the latter category. Longstanding hypergastrinaemia probably plays a causative role in the development of both carcinomas and carcinoids.

An association of carcinoid tumours with another primary neoplasm has been noted in 17 to $53 \%$ of cases. ${ }^{8}$ This is said to reflect enhanced susceptibility to cancer in these patients and may have an important bearing on patient management.

In conclusion, we suggest that carcinoid tumours, though themselves of relatively low malignant potential, may be important as indicators of other unrelated but high risk malignancies. These patients should be closely followed clinically, especially as the incidence of these types of carcinoids appears to be on the increase.

1 Yoshino T, Ohtsuki Y, Shimada Y, Takahashi K, Sonobe H, Hayashi $\mathrm{K}$, et al. Multiple carcinoid tumor combined with Hayashi $\mathrm{K}$, et al. Multiple carcinoid tumor combined with mucosal carcinoma in the stom

2 Bordi C, Yu J-Y, Baggi MT, Davoli C, Pilato F, Baruzzi G, et al. Gastric carcinoids and their precursor lesions. A histologic and immunohistochemical study of 23 cases. Cancer 1991;67:663-72.

3 Ambe K, Mori M, Enjoji M. Early gastric carcinoma with multiple endocrine cell micronests. Am ₹ Surg Pathol 1987; 11:310-15.

4 Ali MH, Davidson A, Azzopardi GJ. Composite gastric carcinoid and adenocarcinoma. Histopathology 1984;8:529-36.

5 Hodges JR, Isaacson P, Wright R. Diffuse enterochromaffinlike (ECL) cell hyperplasia and multiple gastric carcinoids:
lidges a complication of pernicious anaemia. Case report. Gut a complication of

6 Polak JM, Bloom SR. Endocrine tumours of the gut. In: McGee J, Isaacson PG, Wright NA, eds. Oxford textbook of pathology. Vol 2A. Oxford: Oxford University Press, 1992: 1269-75.

7 Rosai J (ed). Gastrointestinal tract/small bowel. In: Ackerman's Sungical pathology. Vol 1. St Louis: CV Mosby, 1989:53941.

8 Brown NK, Smith MP. Neoplastic diathesis of patients with carcinoid. Cancer 1973;32:216-22. 